\title{
Aortic dissection after the Ross procedure
}

\author{
Hanna Siudalska', Mariusz Kuśmierczyk1', Jacek Różański', Joanna Petryka-Mazurkiewicz², Magdalena Kumor³, \\ Anna M Michałowska4', llona Michałowska ${ }^{5}$
}

'Department of Cardiac Surgery and Transplantology, National Institute of Cardiology, Warszawa, Poland

2Department of Coronary and Structural Heart Diseases, National Institute of Cardiology, Warszawa, Poland

${ }^{3}$ Congenital Heart Disease Department, National Institute of Cardiology, Warszawa, Poland

${ }^{4}$ National Institute of Cardiology, Warszawa, Poland

5Department of Radiology, National Institute of Cardiology, Warszawa, Poland

Correspondence to: Ilona M Michałowska, $\mathrm{MD}, \mathrm{PhD}$,

Department of Radiology,

National Institute of

Cardiology,

Alpejska 42, 04-628

Warszawa, Poland,

phone: +48 223434167

e-mail:

imichalowska@ikard.pl

Copyright by the

Author(s), 2021

Kardiol Pol. 2021;

79 (6): 702-703;

DOI: 10.33963/KP.15957

Received:

February 3, 2021

Revision accepted: April 11, 2021

Published online: April 16, 2021
The Ross procedure is performed for the treatment of aortic valve disease in children and young adults. The diseased aortic valve is removed and replaced with the patient's pulmonary valve, and a pulmonary homograft is implanted in the pulmonary position.

The Ross procedure due to outstanding hemodynamic parameters and no need for anticoagulation provides the patients with a better quality of life compared to the patients who have undergone the mechanical aortic valve replacement. The implantation of the autograft in the subcoronary position was first described by Donald Ross. Then the Ross procedure has been modified and shifted toward a full root replacement technique. However, the implantation of pulmonary autograft as a full root may be complicated by dilatation of the autograft caused by systemic pressure higher than pulmonary pressure [1]. In cases of concomitant aortic valve stenosis with a very small aortic annulus or with a narrowed left ventricular outflow tract, the Ross-Rastan-Konno procedure is an option of surgical treatment [2].

We present here a 49-year-old male patient who was admitted to the hospital due to dissection of the aneurysm of the autograft which had been found on follow-up magnetic resonance imaging (Figure 1A) 15 years after the Ross procedure. The indication for the cardiac magnetic resonance imaging was pulmonary autograft widening to $53 \mathrm{~mm}$ identified five months earlier by echocardiography. Implantation of the pulmonary autograft in the aortic position was performed using the root replacement technique. The indication for the Ross procedure was bicuspid aortic valve stenosis. On admission to the hospital, the patient was asymptomatic, in good condition without complaints of chest pain or worsening of physical capacity. Lately, increased blood pressure was observed. Transthoracic echocardiography revealed a left ventricular dilatation to $65 \mathrm{~mm}$, the left ventricular ejection fraction of $55 \%$, dilatation of the autograft to $66 \mathrm{~mm}$ with dissection (Figure 1B-C), moderate autograft valve insufficiency and normal functioning of the pulmonary homograft. Cardiac computed tomography was performed to assess coronary arteries before surgery and showed normal vessels without significant stenosis, a dissection limited to the aneurysm of the autograft (Figure 1D-E) and a normal aortic arch with the descending aorta. The patient was referred for emergency surgery and underwent the Bentall procedure (the autograft and the valve were replaced with a conduit of the aorta and a mechanical valve, Figure 1F). Another option of surgical treatment for pulmonary autograft aneurysm can be one of the aortic valve-preserving procedures - the reimplantation of the native valve within a vascular graft or aortic remodeling of the root with valvuloplasty $[3,4]$. These options were not considered because of degeneration and prolapse of the right coronary cusp of the pulmonary autograft valve. It was not possible to perform repair of autograft valve. The patient's postoperative course was uneventful.

Aortic root or ascending aorta dilatation and aortic regurgitation are relatively common consequences of the Ross procedure, which occur in 20\%-30\%, but dissection of the autograft is a rare complication [5]. To our knowledge, only a few cases of post-Ross procedure aortic dissection have been reported. 


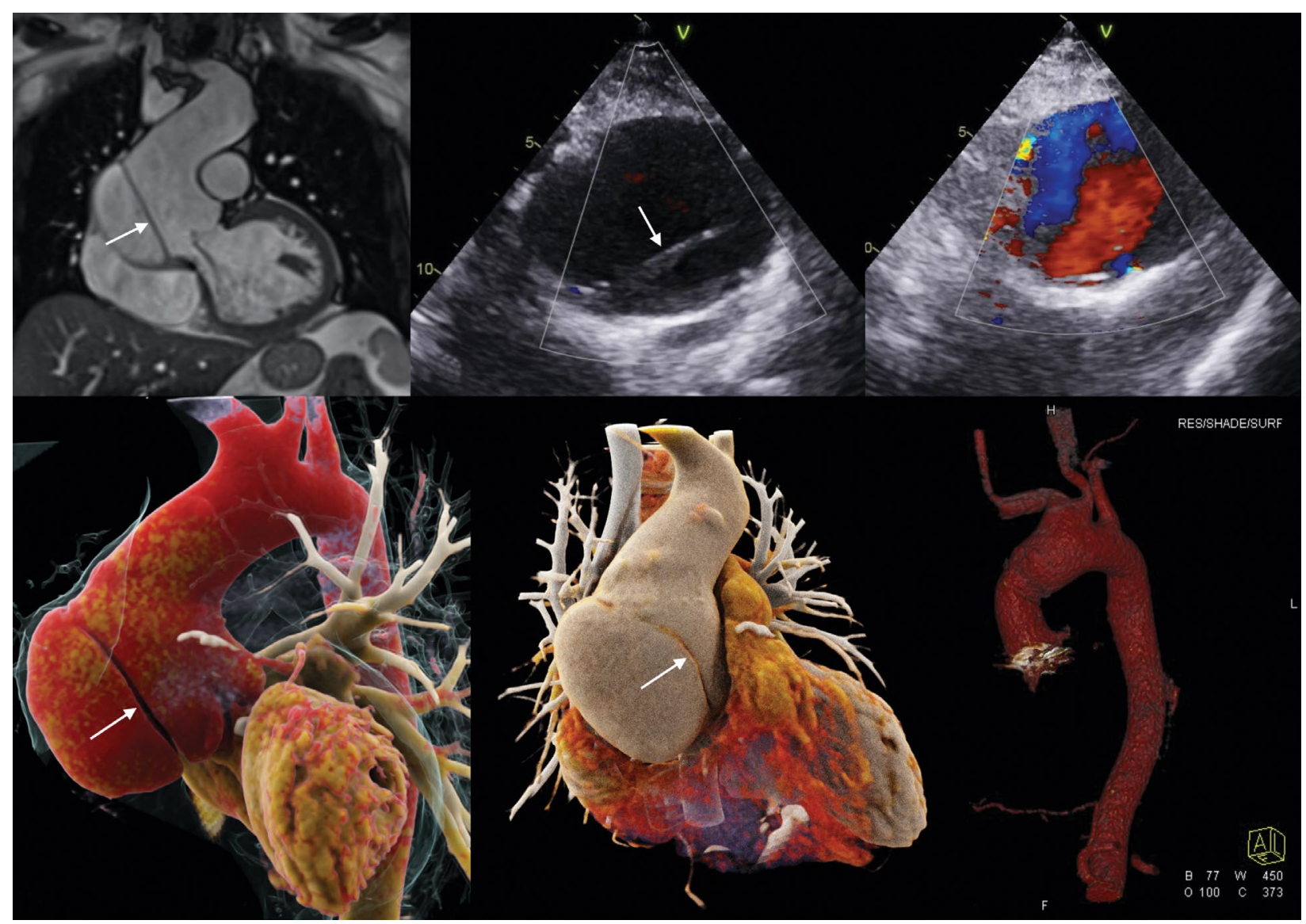

Figure 1. A. Magnetic resonance imaging, balanced steady-state free precession image, orthogonal to left ventricular outflow tract view shows dissection of the aneurysm of the autograft (arrow) and aortic regurgitation jet. B, C. Echocardiography imaging, a modified right parasternal short axis plane of the autograft above the neoaortic valve with dissection (arrow) (B), with color Doppler (C). D, E. Computed tomography angiography, a cinematic rendering reconstruction shows dissection of the aneurysm of the autograft (arrow). F. Computed tomography angiography, volume rendering reconstruction visualizes the thoracic aorta after Bentall procedure

\section{Article information}

Conflict of interest: None declared.

Open access: This article is available in open access under Creative Common Attribution-Non-Commercial-No Derivatives 4.0 International (CC BY-NC-ND 4.0) license, allowing to download articles and share them with others as long as they credit the authors and the publisher, but without permission to change them in any way or use them commercially. For commercial use, please contact the journal office at kardiologiapolska@ptkardio.pl.

How to cite: Siudalska H, Kuśmierczyk M, Różański J, et al. Aortic dissection after the Ross procedure. Kardiol Pol. 2021; 79(6): 702-703, doi: 10.33963/KP.15957.

\section{REFERENCES}

1. Mazine A, El-Hamamsy I, Verma S, et al. Ross procedure in adults for cardiologists and cardiac surgeons: JACC state-of-the-art review. J Am Coll Cardiol. 2018; 72(22): 2761-2777, doi: 10.1016/j.jacc.2018.08.2200, indexed in Pubmed: 30497563.

2. Haponiuk J, Chojnicki M, Paczkowski K, et al. Fetal and neonatal percutaneous aortic balloon valvuloplasty in critical aortic stenosis followed by complex Ross-Rastan-Konno reconstruction. Kardiol Pol. 2019; 77(11): 1087-1088, doi: 10.33963/KP.14973, indexed in Pubmed: 31527562.

3. David TE, Feindel CM. An aortic valve-sparing operation for patients with aortic incompetence and aneurysm of the ascending aorta. J Thorac and Cardiovasc Surg. 1992; 103(4): 617-622, doi: 10.1016/s00225223(19)34942-6, indexed in Pubmed: 1532219.

4. Sarsam MA, Yacoub M. Remodeling of the aortic valve anulus. J Thorac Cardiovasc Surg. 1993; 105(3): 435-438, indexed in Pubmed: 8445922.

5. Luciani GB, Favaro A, Casali G, et al. Reoperations for aortic aneurysm after the Ross procedure. J Heart Valve Dis. $2005 ; 14(6)$ : 766-773, indexed in Pubmed: 16359057. 